\title{
A PESQUISA COMO PRÁTICA ARTÍSTICA: A RAZÃO NA PRÁTICA DE INVESTIÇÃO COMO RAZÃO ARTISTA - UMA POSSÍVEL CONTRIBUIÇÃO DE PIERRE BOURDIEU PARA A ÁREA DAS CIÊNCIAS SOCIAIS E HUMANAS NA SAÚDE
}

\author{
RESEARCH AS AN ARTISTIC PRACTICE: THE REASON OF A RESEARCH \\ LIKE ARTIST REASON - A POSSIBLE CONTRIBUTION OF PIERRE \\ BOURDIEU TO THE FIELD OF HUMAN AND SOCIAL SCIENCES IN \\ HEALTH
}

\section{Madel Therezinha Luz}

Programa de Pós-Graduação em Saúde Coletiva, Universidade Federal do Rio Grande do Sul E-mail:madelluz@uol.com.br

\section{Cesar Sabino}

Departamento de Estudos Políticos, Universidade Federal do Estado do Rio de Janeiro

E-mail: cesarsabino@hotmail.com

\section{Resumo}

Analisa-se a proposta metodológica de Pierre Bourdieu na prática do pesquisar como agir social e como um trabalho de equipe, semelhante ao do esporte. Na proposta metodológica de Bourdieu, à razão teórica, tradicionalmente ligada à pesquisa científica, sobrepõe-se uma racionalidade expressiva, artística, mutável, emergente da pesquisa como construção social, em que os agentes pesquisadores são modificados pelo objeto de pesquisa, tanto quanto modificam o objeto pesquisado durante todo o processo de investigação. Examina-se o papel inovador desta proposta para a investigação científica em ciências humanas, em especial no caso das ciências sociais e humanas na saúde e no campo específico da saúde coletiva.

Palavras-chave: Metodologia da Pesquisa; Arte e Pesquisa; Prática Social; Ciências Sociais e Humanas na Saúde; Saúde Coletiva. 


\section{Abstract}

We analyzed Pierre Bourdieu methodology performed to develop researches in social intervention as a teamwork or a team spirit. This methodology, theoretical reasoning and traditionally related to scientific researches, overlaps an expressive rationality that is artistic, changeable, emerging from researches as a social process. The researchers are touched by the studied object, as long as this object touches the researchers during the investigation process. We looked at a new perspective of this method for a Human Science survey, especially in case of Social and Human sciences related to health and specifically in the Public Health sphere.

Keywords: Research Methodology; Art and Research; Social Practice; Human and Social Sciences in Health; Public Health.

\section{Introdução}

Estas notas pretendem ser uma paráfrase à atitude metodológica de Pierre Bourdieu em seu trabalho de atividade de pesquisa em sociologia, visto por ele como um agir social, ao mesmo tempo complexo na elaboração (conceitual) e concreto no passo a passo da construção (da empiria). Próximo, portanto, da arte, quando esta constrói em linguagem inovadora seus objetos materiais de expressão. Esta atitude está presente sobretudo nas obras das duas décadas que precederam sua morte, podendo ser caracterizadas pela referência de sua produção teórica a resultados de uma prática social específica, não raro coletiva, certamente grupal, em que a relação sujeito/objeto tradicional se desvanece face ao encontro do pesquisador com a realidade dos "sujeitos" que investiga., 1,2,3,4 Preferimos empregar a expressão originariamente francesa sujet porque ela exprime melhor que "objeto" a ideia de um tema de investigação a ser construído como objeto ao longo do caminhar da pesquisa, sendo neste caso mais um "sujeito" que um "objeto", pois interage continuamente com o pesquisador no processo da investigação, modificando suas hipóteses iniciais, reorientando seus procedimentos metodológicos, suas suposições empíricas, ou suas interpretações teóricas, podendo até mesmo mudar sua visão de mundo.

A ideia francesa de "sujeito" de pesquisa, que corresponde a um assunto estruturado, claramente definido, mais que a um tema de pesquisa - como é frequentemente traduzido - afasta um pouco a coisificação do processo, implícita na ideia do tradicional "objeto de pesquisa". Mais adiante voltaremos a este assunto. Estas notas pretendem também referir-se a certa postura anti "metodologista", e anti "teoricista" adotada pelo autor, quando este filiava a ordenação de esquemas conceituais, métodos e técnicas à prática da construção dos objetos a pesquisar, ligando deste modo a seleção de instrumentos teóricos e empíricos da pesquisa à concepção da investigação sociológica como atividade social, embora a visse sempre em perspectiva processual, isto é, atividade situada em contextos histórico-culturais em constante construção e mudança. Atividade que supõe, portanto, um tema ou "sujeito/ tema" (sujet) de investigação em interação processual constante entre o "objeto" (o quê ou quem é investigado) e o "sujeito" (quem investiga, isto é, o pesquisador, seja ele individual ou grupal).

Embora tenha como base dessas notas certas obras deste autor que foi, sem sombra de dúvida, um dos maiores nomes das Ciências Sociais na segunda metade do século $X X$, este não é um trabalho de 
"especialistas" em Pierre Bourdieu: seja sobre sua metodologia, seja sobre a teoria do autor. Nem poderia sê-lo, uma vez que a base bibliográfica utilizada para estas notas é muito restrita, pobre mesmo, levando-se em consideração a extensa lista de livros, e a abundância de artigos escritos apenas pelo sociólogo; sem mencionar outros tantos artigos e livros escritos, em suas quatro décadas de atividades, em colaboração com discípulos, ou outros pesquisadores. . $^{5,6,7,8,9,10.1}$ Apenas no campo da elaboração conceitual, Bourdieu nos brindou com vários conceitos chave para as ciências sociais, como os de campo (em que pesem seus opositores, por sua abrangência), poder (ou dominação) simbólico, habitus, capital cultural lou social), entre tantas outras ferramentas conceituais.

Trata-se de reafirmar aqui, mais simplesmente, inspirados na obra de Bourdieu, a prioridade, para a geração do conhecimento sócio-antropológico, e das ciências humanas em geral, da atividade da pesquisa, portanto da prática da teoria através da contínua construção dos "sujeitos" (temas) de investigação. Submete-se, assim, a lógica da produção do conhecimento ao trabalho da construção concreta de instrumentos conceituais e metodológicos, os quais derivam do - ou se aperfeiçoam no - processo do desenvolvimento da atividade de investigação, seja ela de início conceitual ou empírica. ${ }^{11}$ Com esta atitude procurase eliminar, ou pelo menos combater, o duplo vício, historicamente presente nas ciências sociais - apenas parcialmente superado - do teoricismo, que propõe esquemas conceituais prévios que visam a enquadrar os projetos teoricamente,

\footnotetext{
i Por exemplo, apenas na obra Réponses, aparecem listados numa contracapa interior 23 livros de Bourdieu, de sua autoria apenas, ou com outros autores. Na parte bibliográfica do livro, aparecem oito páginas (245-253) listadas por ano de trabalhos de Bourdieu, com ou sem coautoria. Deve-se reconhecer que o livro é de 1992 e que o autor continuou a produzir até sua morte ocorrida em 23 de janeiro de 2002.
}

"formatando" objetos de pesquisa antes mesmo que estes sejam construídos, e do metodologismo, como um discurso formal de enquadramento de abordagens do objeto, que tem constituídos um conjunto a priori de métodos e técnicas ditos qualitativos ou quantitativos, às vezes contrapostos em dicotomias falaciosas.

Estes instrumentos "prévios" funcionaram historicamente como camisas de força metodológicas, formatadoras de procedimentos relativos aos sujeitos de investigação em construção, que acabaram funcionando como obstáculos epistemológicos, ao invés de elucidar questões teóricas ou propiciar a resolução prática de problemas na área social. Em outras palavras, pretende-se afirmar nestas notas, coerentemente com a postura de Bourdieu, que a atividade da pesquisa vista como prática social em construção é a verdadeira matriz geradora dos instrumentos conceituais e metodológicos úteis às ciências sociais. Estes instrumentos, em elaboração no projeto, ou por ele elaborada, podem e devem ser utilizados no processo da pesquisa como caixa de ferramentas - boite à outils. ${ }^{10: 30-34,12: 30-48}$

\section{A Pesquisa científica como uma arte de produzir conhecimento}

Não seria adequado que o termo científica fosse tomado neste contexto como geralmente o é, isto é, como um adjetivo, literalmente qualificativo, um juízo de valor epistemológico, que atribui toda a autoridade intelectual/cognitiva à ciência contemporânea como produtora legítima, única mesmo, de verdades propositivas, já testadas ou não. Como poderia afirmar Foucault, de positividades. Em outras palavras, de conhecimento. Pretende-se referir aqui a um modo historicamente específico de produção de afirmações, 
descritivas, explicativas ou mesmo interpretativas de eventos, situações e relações (ou estruturas de relações) específicas, isto é, envolvendo os diversos campos do viver e do agir humanos. Produção que busca, certamente, rigor, coerência, consistência e distância axiológica como fonte epistemológica e ética para a descrição, a compreensão, a interpretação, e mesmo a explicação de eventos, situações, ações e relações sociais. ${ }^{13}$

A referência principal, no caso dessas notas, é às humanidades, mais limitadamente às disciplinas conhecidas como ciências sociais (sociologia, antropologia, história, política, demografia etc.), embora se acredite que o conjunto das disciplinas das ciências ditas naturais, ou físicas, poderia ter o mesmo objetivo e atitudes diante da sua própria positividade científica. Sobretudo em uma época em que a pesquisa, como atividade cognitiva, tende a tornar-se cada vez mais interdisciplinar, e mesmo transdisciplinar, implicando disciplinas de campos distintos (físicas, naturais, humanas), na medida em que o paradigma dominante na ciência está se voltando para a invenção e a intervenção tecnológicas, isto é, para a inovação, através da recriação contínua de modos de viver, produzir e consumir. ${ }^{14}$ Neste sentido, o caráter interdisciplinar da contribuição de Bourdieu beneficiaria, fortemente, o subcampo das ciências sociais em saúde, e por conseqüência, a própria Saúde Coletiva como face interdisciplinar de saberes/ práticas em saúde.

Acredita-se ser este o núcleo constitutivo comum de racionalidade e ética do que se poderia chamar, referindose à categoria elaborada por Bourdieu, de campo científico. Embora se saiba que Pierre Bourdieu estudou preferencialmente o campo científico do ponto de vista da sociologia, isto é, em termos da distribuição do poder simbólico, das estratégias e lutas histórico-sociais dos agentes e grupos na disputa por lugares de controle neste campo específico (que analisou durante toda sua trajetória acadêmica)ii, aqui a referência é a um ethos da prática científica como um todo, do agir comum a qualquer campo do conhecimento que se manifeste através da pesquisa, e que é visto como ponto de partida do trabalho de cada pesquisador, gerando um habitusiii específico neste agente, se ele pretender ser admitido ou mantido como um ator em seu campo de pesquisa. $^{\text {iv }}$

$\mathrm{O}$ que se tenta também demonstrar neste texto é que esta atividade, teórico prática, de produção de conhecimento verificável, apresenta, em aparente paradoxo, as características de uma arte, sobretudo quando é praticada por um autor, como Bourdieu, que produz o conhecimento dito ciência, enquanto $o$ produz, no processo mesmo da produção. A atividade da pesquisa se revela, neste caso, como criação artística, ou pelo menos como uma artesania, em que o coordenador de

ii Não por acaso, Bourdieu afirmou, figurativamente, ser a Sociologia um "esporte de combate". Sendo este o nome de um documentário realizado por ele. ${ }^{2}$ iii Uma das categorias analíticas centrais elaboradas por Bourdieu, a de habitus, é entendida como: "As estruturas constitutivas de um tipo particular de meio (as condições materiais características de uma condição de classe), que podem ser apreendidas empiricamente sob a forma de regularidades associadas a um meio socialmente estruturado, produzem habitus, sistemas de disposições duráveis, estruturas estruturadas predispostas a funcionar como estruturas estruturantes, isto é, como princípio gerador e estruturador das práticas e das representações que podem ser objetivamente 'reguladas' e 'regulares' sem ser o produto da obediência às regras, objetivamente adaptadas a seu fim sem supor a intenção consciente dos fins e o domínio expresso das operações necessárias para atingi-los e coletivamente orquestradas sem ser o produto da ação organizadora de um regente" (Grifo do autor). ${ }^{15}$

iv É claro que este ethos é frequentemente posto em questão e desrespeitado pela norma vigente na produção acadêmica, que é a competição entre os agentes trabalhadores da pesquisa na busca de sucesso individual como marca da competência e estratégia de luta para alcançar o topo da hierarquia na instituição locus básico da produção científica. ${ }^{16}$ 
uma pesquisa funciona como um "diretor", de modo similar a um diretor artístico, ou a um mestre artesão, ou mesmo como um treinador esportivo (um "coach"), e seu grupo de pesquisa deve funcionar como "time" - uma equipe de colaboradores, tal como nas artes e nos esportes, e seu laboratório ou unidade de pesquisav deve tender a funcionar como um atelier, mais do que como o histórico laboratório disciplinar, tradicional desde o final do século XIX.

Em outras palavras, o conhecimento é produzido em conjunto e apropriado coletivamente, a partir do ensinar a fazer e do dirigir típico de um "mestre artesão", ou de um "coach" (técnico esportista) isto é, o propósito, no caso, é ensinar a criar conhecimento através de uma prática que se aprende ao praticar: uma práxis grupal. O que é comum nas artes cênicas, e naquelas em que o coletivo ou o grupo é fundamental, como a dança, ou a música sinfônica, por exemplo. O mesmo pode ser dito dos esportes em que a equipe, o "time" deve ser o ator, e não o indivíduo, sob pena de perda de eficácia, face à quebra da unidade do conjunto. A competição entre os membros do grupo é lesiva ao "time" como um todo, seja na ciência, na arte, ou no esporte.

Uma equipe de pesquisa, neste sentido, passa a ser um time jogando, geralmente num "esporte competitivo", como a atividade acadêmica, onde geralmente, mas não unicamente se produz ciência, ou mesmo técnica. Certamente cada "jogador" tem seu papel, e sua competência será avaliada pelo conjunto dos "jogadores" e "treinadores", mas isto não significa que não haja "times" atuando sem espírito de

\footnotetext{
v A referência às expressões obrigatórias "laboratoire" ou "unité" de pesquisa situa uma realidade tipicamente francesa: é forçoso reconhecer que as equipes ou grupos de pesquisa, mesmo nas Ciências Sociais, são a realidade histórico-institucional dominante, o que não é o caso brasileiro, mesmo se considerando as transformações na gestão de ciência e tecnologia das últimas décadas.
}

conjunto, nos quais a competição entre os agentes torna-se mais importante, através da busca individual por sucesso e status, quebrando 0 ethos necessariamente coletivo da ciência.

$\mathrm{Na}$ produção científica atual, multiplicam-se as denúncias de quebra do ethos científico, em proveito do sucesso individual e de vantagens estatutárias e pecuniárias associadas a este sucesso. A lógica da atividade da pesquisa em grupo como fundamento da produção original - coletiva, portanto - do conhecimento, seja nas ciências sociais em saúde, seja no campo ampliado da Saúde Coletiva, que reúne áreas disciplinares oriundas de vários campos diversos, e mesmo saberes tradicionais, bem como distintas práticas técnicas, tem, a nosso ver, uma contribuição potencial importante nos conceitos e na proposta metodológica da pesquisa como uma prática "de arte" aportados por Pierre Bourdieu às ciências sociais. 


\section{Referências}

1. Bourdieu P. Os usos sociais da ciência: por uma sociologia clínica do campo científico. São Paulo: Unesp; 2004.

2. Bourdieu P. Meditações pascalianas. Rio de Janeiro: Bertrand Brasil; 2001.

3. Bourdieu P. Sobre o Estado: cursos do Collège de France (1989-1992). São Paulo: Companhia das Letras; 2014.

4. L' Estoile B. Entrar no jogo: a ciência como crença. In: Encrevè P; Lagrave RM (Org.). Trabalhar com Bourdieu. Rio de Janeiro: Bertrand Brasil; 2005.

5. Bourdieu P. O poder simbólico. Lisboa: DIFEL; 1989.

${ }^{6}$. Bourdieu P. La misére du monde. Paris: Seuil; 1993.

7. Bourdieu P. Razões práticas: sobre a teoria da ação. Campinas: Papirus; 1996.

8. Bourdieu P. A produção da crença: contribuição para uma economia dos bens simbólicos. São Paulo: Zouk; 2004.

9. Bourdieu P. A economia das trocas lingüísticas: o que falar quer dizer. São Paulo: EDUSP; 2008.

10. Bourdieu P, Wacquant L. Réponses: pour une anthropologie reflexive. Paris: Seuil; 1992.

11. Bourdieu P, Chamboredon JC, Passeron JC. Le métier du sociologue: préalables épistémologiques. Paris: De Gruyter; 2005.

12. Bourdieu P. Questões de sociologia. Rio de Janeiro: Marco Zero; 1983.

${ }^{13}$. Foucault M. Nietzsche, a genealogia e a história. In: Foucault M. Microfísica do poder. Rio de Janeiro: Graal; 1989.

14. Vandenberghe F. O Real é relacional. In: Vandenberghe F. Teoria social realista: um diálogo franco-britânico. Belo Horizonte: UFMG; 2010.

15. Bourdieu P. Esboço de uma teoria da prática. In: Ortiz, R.; Fernandes, F (Org.). Pierre Bourdieu. São Paulo: Ática; 1983. (Coleção Grandes Cientistas Sociais, n. 39)

16. Bourdieu P. O campo científico. In: Ortiz R, Fernandes F. (Orgs.). Pierre Bourdieu. São Paulo: Ática; 1983. (Coleção Grandes Cientistas Sociais, n. 39). 